\title{
Visual Outcome and Predictors of Poor Visual Outcome among Uveitis Patients Attended at KCMC Eye Department, Moshi-Northern Tanzania
}

\author{
Abrahamo Arao Nhutene Matova1 ${ }^{(1)}$, William Makupa ${ }^{1,2}$ \\ ${ }^{1}$ Kilimanjaro Christian Medical University College (KCMUCo), Moshi, Tanzania \\ ${ }^{2}$ Kilimanjaro Christian Medical Center Hospital, Moshi, Tanzania \\ Email: matova.abrahamo@gmail.com,makupauw@yahoo.com
}

How to cite this paper: Matova, A.A.N. and Makupa, W. (2020) Visual Outcome and Predictors of Poor Visual Outcome among Uveitis Patients Attended at KCMC Eye Department, Moshi-Northern Tanzania. Open Journal of Ophthalmology, 10, 123-132. https://doi.org/10.4236/ojoph.2020.102014

Received: March 21, 2020

Accepted: May 8, 2020

Published: May 11, 2020

Copyright $\odot 2020$ by author(s) and Scientific Research Publishing Inc. This work is licensed under the Creative Commons Attribution International License (CC BY 4.0).

http://creativecommons.org/licenses/by/4.0/ (c) (i) Open Access

\begin{abstract}
Background: Uveitis, an inflammatory disease of the middle layer of the human eye is a potentially blinding disease, carrying social, economic and individual consequence. Though not being a leading blinding disease, it causes visual impairment and blindness with its complications like cataract and glaucoma. Few studies have addressed the visual outcome after diagnoses and follow-up of patients with uveitis; and at our setting, few is known about the visual outcome, factors predicting poor outcome. Methodology and Materials: This was a hospital-based cohort study conducted at the Kilimanjaro Christian Medical Center (KCMC), Eye Department. Files of patients attended from January 2010 to December 2017 were assessed. Measures of Central Tendency and their corresponding dispersion were used to summarize continuous variables and proportions for categorical variables. One sample paired t-test was used to assess differences in mean Best Corrected Visual Acuity (BCVA) and Wilcoxon Signed Rank test for differences in median BCVA between the first visit and at one year respectively. Association between predictors and poor outcome was analyzed by using Chi square test. Multivariate regression was used to control for potential confounders and a p value less than 0.05 was considered as statistical significant. Results: A total of 291 patients were assessed, majority of them being female (54.6\%), with median age being 53 years. The proportion of visual impairment reduced from the initial $57.7 \%$ at presentation to $28.2 \%$ at one year. The mean BCVA improved from the initial $0.96 \log$ MAR to $0.70 \log$ MAR at one year. The main factors associated with poor presenting vision were: Cataract ( $\mathrm{p}$ value $<0.001$ ), Cystoid Macular Edema (CME: $\mathrm{p}$ value $<0.001$ ), Maculopathy ( $\mathrm{p}$ value $=0.042)$, Keratopathy ( $\mathrm{p}$ value $<0.001$ ),
\end{abstract}


Posterior Synechiae (PS: $\mathrm{p}$ value $=0.044)$, Abnormal Intraocular Pressure (IOP: $\mathrm{p}$ value $=0.036)$ and non-anterior location $(\mathrm{p}$ value $=0.042)$. At one year, the factors associated with poor outcome were: retinal detachment ( $\mathrm{p}$ value $=0.022)$, Glaucoma ( $\mathrm{p}$ value $=0.018)$ and Maculopathy $(\mathrm{p}$ value $=0.039)$. Conclusions: at one year of follow-up of patients with uveitis, the proportion of visual impairment reduces significantly, with improvement also being observed on mean visual acuity. The most common predictors of poor visual outcome were Cataract, Glaucoma CME, abnormal IOP and Maculopathy.

\section{Keywords}

Visual Outcomes, Predictors, Uveitis

\section{Introduction}

Uveitis refers to the inflammation of the uveal tract, which is the middle vascular coat of the eye, lying between the sclera and neuro-epithelium. This includes inflammation of the iris, ciliary body, and choroid. When other parts of the eye are affected (such as retina) is also referred to as uveitis [1] [2] [3].

Uveitis is the third leading cause of blindness in developed countries and it is a potentially blinding condition that can result in serious complications in the eyes [4]. Uveitis is estimated to account for approximately $10 \%$ of visual handicap in the western world and is responsible for 30,000 new cases of legal blindness each year. Prevalence of uveitis varies according to the anatomical location. The frequency of pan-uveitis varies among countries but it appears to be more common in African, Asian, and South American countries than in Western countries [3].

Previous studies were conducted to find factors associated with visual impairment among uveitic patients and it was found that cataract, CME, and Glaucoma were the main factors among others [5]-[10].

Corticosteroids represent the primary therapeutic modality in patients who have non-infectious uveitis. These medications produce a broad suppression of the immune system. Immunomodulatory therapy plays an important role in the treatment of severe non-infectious uveitis, particularly in patients who have not responded adequately to, or who develop side effects from corticosteroid therapy and they are generally indicated in patients who require chronic (e.g., longer than 6 months) corticosteroid therapy at doses greater than $10 \mathrm{mg}$ of prednisone per day or the equivalent [1].

This study intended to assess the proportion of visual impairment at presentation and at one year, as well as changes of visual acuity and the predictors of poor visual acuity at one year. The obtained results may be used as reference in future studies in similar settings as ours, given that most of other studies were conducted in middle to higher income countries and the realities might be quite different. 


\section{Methodology}

\subsection{Study Design and Area}

This was a retrospective hospital-based cohort study, looking at patients attending KCMC eye department from 2010 to 2017 to whom the diagnosis of uveitis was made. KCMC is a regional referral hospital located in Moshi, Kilimanjaro region Northern Tanzania, serving over 15 million people of the northern region of Tanzania. It serves five regions, namely, Kilimanjaro, Arusha, Manyara, Tanga and Singida. The eye department has a capacity of 36 beds, nine full time working ophthalmologists.

\subsection{Study Population}

All patients attending KCMC Eye department from January 2010 to December 2017 with active uveitis at the beginning of the follow-up period and a minimum follow-up period of one year.

Active uveitis was defined as follows: cells or flare in anterior chamber; vitreous activity (vitreous cellularity, snow balls or snow-banking) or chorio-retinal lesions with indistinct borders or presence of active vasculitis. Excluded were patients with missing key information (visual acuity) at initial and end of follow up period and those younger than 18 years of age.

\subsection{Variables}

Independent variables: sociodemographic characteristics (age, sex, history of trauma and co-morbidities); location of the disease; laterality; duration of disease activity and previous surgeries.

Dependent variable was best corrected visual acuity at presentation and at 12 months of follow-up.

\subsection{Data Collection}

Files of patients attended and diagnosed with uveitis were retrieved from the department electronic system (registry). The patient's files fulfilling criteria (patients with active uveitis, older than 18 years, with complete information on the files) to be included in the study were used by the investigator to collect data into the appropriate data sheet. Finally, data was entered into the SPSS version 23.

\subsection{Data Analysis}

Categorical variables were presented in tables and graphs and summarized by using proportions. Numerical variables were presented using graphs and summarized using appropriate measures of central tendency and correspondent measures of dispersion and categorical as proportions. One sample paired t-test and Wilcoxon Signed Rank test were used to assess the difference between the mean BCVA and Median BCVA respectively at the beginning and at end of the fol- 
low-up period. The association between the predictors and poor outcome was assessed by using Chi square test. Multivariable analysis was used to control for confounders. A $p$ value of $<0.05$ was used for statistical significance.

\subsection{Ethical Consideration}

Ethical clearance number 2359 for this study was granted from KCMUCo Ethical committee board.

\section{Results}

\subsection{Socio-Demographic and Clinical Characteristics of the Study Participants}

A total of 291 patients fit the inclusion criteria and of these $54.6 \%$ were females, with the median age being 53 years at diagnosis (IQR 40 - 64); the youngest and oldest subject being 19 years and 88 years respectively (see Table 1 ).

\subsection{Proportions of Visual Impairment and Mean Best Corrected Visual Acuity at First Visit and at 12 Months of Follow up (Visual Outcomes)}

Out of the 291 patients who were followed-up, 57.7\% had visual impairment at presentation, the proportion decreased to $28.2 \%$ at 12 months of follow up (Table 2). These changes were observed in all categories of visual impairment categories, especially from the subcategory of severe visual impairment, where $76.5 \%$ of all those who presented (at first visit) with impaired vision in this category had normal vision at 12 months, followed by moderate visual impairment (73.1\%) and lastly by blindness (63.1\%) (Table 3 ).

The Overall mean log MAR BCVA at first visit was $0.96 \log$ Mar $(\mathrm{SD}=1.02)$ and at $12^{\text {th }}$ visit increased to $0.70 \log$ MAR $(S D=1.07)$; with mean difference of 0.26, ( $\mathrm{p}$ value $<0.001$ ) and the median BCVA was $0.5 \log$ MAR at presentation and increased to $0.3 \log$ MAR at one year (median difference $0.2, \mathrm{p}$ value $<$ $0.001)$.

\subsection{Predictors of Poor Visual Acuity at Presentation}

In the univariate analysis of factors contributing to poor vision at first visit, the following factors were found to be statistical significant associated with poor presenting vision: Cataract $\left(\chi^{2}=32.25, \mathrm{p}\right.$ value $\left.<0.001\right)$; Glaucoma $\left(\chi^{2}=6.24, \mathrm{p}\right.$ value-0.012); $\operatorname{CME}\left(\chi^{2}=7.58, \mathrm{p}\right.$ value 0.006$)$; Abnormal IOP $\left(\chi^{2}=20.08\right.$, $\mathrm{p}$ value $<0.001)$; Keratopathy $\left(\chi^{2}=19.15, \mathrm{p}\right.$ value $\left.<0.001\right)$; Posterior Synechiae $\left(\chi^{2}=\right.$ 12.26 , $\mathrm{p}$ value $<0.001)$; non-anterior location $\left(\chi^{2}=11.62\right.$, $\mathrm{p}$ value $\left.<0.001\right)$; Anterior Chamber cells $>2+\left(\chi^{2}=12.27\right.$, $\mathrm{p}$ value $\left.<0.001\right)$; Anterior chamber flare $2+$ $\left(\chi^{2}=5.51, \mathrm{p}\right.$ value $\left.=0.022\right)$ and two or more factors $\left(\chi^{2}=17.91, \mathrm{p}\right.$ value $\left.<0.001\right)$. Age ( $\mathrm{p}$ value 0.47 ), Sex ( $\mathrm{p}$ value 0.32 ); history of trauma ( $\mathrm{p}$ value 0.15 ); Retinal Detachment ( $p$ value 0.075 ); Papillitis ( $p$ value 0.64 ); were not statistically significant associated with poor presenting vision (see Table 4). 
When the multivariable analysis was performed, only Cataract $\left(\chi^{2}=33.69, \mathrm{p}\right.$ value $<0.001)$; $\operatorname{CME}\left(\chi^{2}=13.75\right.$, $\mathrm{p}$ value $\left.<0.001\right)$; Maculopathy $\left(\chi^{2}=4.14\right.$, $\mathrm{p}$ value $0.042)$; Keratopathy $\left(\chi^{2}=34.14\right.$, p value $\left.<0.001\right)$; Abnormal IOP $\left(\chi^{2}=4.11, \mathrm{p}\right.$ value $=0.036)$; Posterior Synechiae $\left(\chi^{2}=4.06, \mathrm{p}\right.$ value $\left.=0.044\right)$ and non-anterior location $\left(\chi^{2}=4.12\right.$, $\mathrm{p}$ value $\left.=0.042\right)$ retained the statistical significance $($ Table 5$)$.

\subsection{Predictors of Poor Outcome at 12 Months of Follow-up}

Univariate analysis of factors associated with poor vision at 12 months of follow-up, found the following factors to be statistical significant associated with poor vision at 12 months: anatomical location $\left(\chi^{2}=13.92\right.$, p value 0.003$)$; Glaucoma $\left(\chi^{2}=8.61, \mathrm{p}\right.$ value 0.003); Retinal Detachment $\left(\chi^{2}=8.91, \mathrm{p}\right.$ value 0.007$)$ and Maculopathy ( $\chi^{2}=7.11, \mathrm{p}$ value 0.008$)$. See Table 6 .

After performing the multivariable analysis, non-anterior location lost the statistical significance, while Glaucoma $\left(\chi^{2}=5.63\right.$, $\mathrm{p}$ value $\left.=0.018\right)$, Retinal Detachment $\left(\chi^{2}=5.22, \mathrm{p}\right.$ value $\left.=0.022\right)$ and Maculopathy $\left(\chi^{2}=4.27, \mathrm{p}\right.$ value $=$ 0.039 ), retained the statistical significance (Table 7).

Table 1. Socio-demographics of patients with uveitis attended at KCMC Eye Department for $\geq 12$ months from 2010-2017 $(\mathrm{N}=291)$.

\begin{tabular}{cc}
\hline Variables & $\mathrm{N}(\%)$ \\
Sex & $132.0(45.4)$ \\
Male & $159.0(54.6)$ \\
Female & \\
Age & $125.0(43.0)$ \\
$<50$ & $166.0(57.0)$ \\
$\geq 50$ & \\
Median 53 years (IQR 40-64) & \\
Provenience & $208.0(71.5)$ \\
Kilimanjaro & $52.0(17.9)$ \\
Arusha & $6.0(2.1)$ \\
Tanga & $9.0(3.1)$ \\
Manyara & $16.0(5.5)$ \\
Others & \\
Ethnicity & $185.0(63.6)$ \\
Chagga & $31.0(10.7)$ \\
Pare & $11.0(3.8)$ \\
Maasai & $64.0(22.0)$ \\
Others & \\
Occupation & $138.0(47.4)$ \\
Peasant & $22.0(7.6)$ \\
Business & $43.0(14.8)$ \\
Employed & $16.0(5.5)$ \\
Student & $72.0(24.7)$ \\
Null & \\
\hline & \\
\hline & \\
\hline & \\
\hline & \\
\hline
\end{tabular}


Table 2. Proportion of visual outcome of patients with uveitis at presentation and at 12 months of follow-up, at KCMC Eye Department 2010-2017 ( $\mathrm{N}=291)$.

\begin{tabular}{ccc}
\hline Variable & $\begin{array}{c}\text { At presentation } \\
\mathrm{n}(\%)\end{array}$ & At 12 months of follow-up \\
& $123(42.3)$ & $\mathrm{N}(\%)$ \\
\hline$>6 / 18$ & $67(23.0)$ & $209(71.8)$ \\
$6 / 18$ to $<6 / 60$ & $17(5.8)$ & $5(14.8)$ \\
$\leq 6 / 60$ to $>3 / 60$ & $84(28.9)$ & $34(11.7)$ \\
$\leq 3 / 60$ to NPL & & \\
\hline
\end{tabular}

Table 3. Visual acuity categories changes over 12 months of follow-up among uveitis patients attended at KCMC Eye Department from 2010-2017 ( $=291)$.

\begin{tabular}{cccccc}
\hline & & \multicolumn{4}{c}{ VA categories at 12 months } \\
\cline { 3 - 6 } & & NVI & MVI & SVI & Blindness \\
\hline \multirow{3}{*}{$\begin{array}{c}\text { VA categories at } \\
\text { presentation }\end{array}$} & NVI & $94(76.4 \%)$ & $13(10.6 \%)$ & $1(0.8 \%)$ & $15(12.2 \%)$ \\
& SVI & $49(73.1 \%)$ & $10(14.9 \%)$ & 0 & $8(11.9 \%)$ \\
& Blindness & $53(63.1 \%)$ & $17(20.2 \%)$ & $4(4.8 \%)$ & $10(11.9 \%)$ \\
\hline
\end{tabular}

Table 4. Univariate analysis of factors associated with visual impairment at presentation among patients with uveitis attended at KCMC Eye Department from 2010-2017 (N = 291).

\begin{tabular}{|c|c|c|c|}
\hline $\begin{array}{l}\text { Main predictors of visual } \\
\text { Impairment }\end{array}$ & $\mathrm{N}(\%)$ & OR $(95 \% \mathrm{CI})$ & $\chi^{2}(\mathrm{p}$ value $)$ \\
\hline Age $\geq 50$ years & $99.0(59.6)$ & $1.20(0.75-1.92)$ & $0.58(0.47)$ \\
\hline Sex (female) & $96.0(60.4)$ & $1.27(0.79-2.02)$ & $1.00(0.32)$ \\
\hline History of trauma & $26.0(68.4)$ & $1.69(0.82-3.51)$ & $2.46(0.15)$ \\
\hline Cataract & $54.0(90.0)$ & $9.24(3.82-22.31)$ & $32.25(<0.001)$ \\
\hline Glaucoma & $31.0(75.6)$ & $2.56(1.20-5.44)$ & $6.25(0.012)$ \\
\hline CME & $10.0(100)$ & & $7.58(0.006)$ \\
\hline $\mathrm{RD}$ & $5.0(100)$ & & $3.73(0.075)$ \\
\hline Abnormal IOP & $57.0(80.3)$ & $4.07(2.14-7.73)$ & $20.08(<0.001)$ \\
\hline Maculopathy & $11.0(84.6)$ & $4.24(1.02-19.48)$ & $4.03(0.045)$ \\
\hline Keratopathy & $24.0(100)$ & & $19.15(<0.001)$ \\
\hline Posterior Synechiae & $27.0(87.1)$ & $5.70(1.94-16.74)$ & $12.26(<0.001)$ \\
\hline Papillitis & $3.0(75.0)$ & $2.22(0.22-21.58)$ & $0.50(0.64)$ \\
\hline Anatomical location & & $3.18(1.60-6.34)$ & $11.62(0.001)$ \\
\hline Anterior & $125.0(53.0)$ & & \\
\hline Non-anterior & $43.0(78.2)$ & & \\
\hline Two or more factors & $43.0(84.3)$ & $4.95(2.31-10.92)$ & $17.91(<0.001)$ \\
\hline AC activity (cells) & & $3.53(1.69-7.38)$ & $12.27(<0.001)$ \\
\hline$\leq 2+$ & $128.0(53.1)$ & & \\
\hline$>2+$ & $40.0(80.0)$ & & \\
\hline AC activity (flare) & & & $5.51(0.022)$ \\
\hline$\leq 2+$ & $161.0(56.7)$ & & \\
\hline$>2+$ & $7.0(100.0)$ & & \\
\hline Previous surgery & $34.0(63.0)$ & $1.31(0.71-2.40)$ & $0.74(0.39)$ \\
\hline
\end{tabular}


Table 5. Multivariable analysis of factors associated with visual impairment at presentation, among patients with uveitis attended at KCMC Eye Department from 2010-2017 (N = 291).

\begin{tabular}{cc}
\hline Main predictors of visual Impairment & $\chi^{2}(\mathrm{p}$ value $)$ \\
\hline Cataract & $33.69(<0.001)$ \\
Glaucoma & $2.74(0.098)$ \\
CME & $13.75(<0.001)$ \\
Maculopathy & $4.14(0.042)$ \\
Keratopathy & $34.14(<0.001)$ \\
Abnormal IOP & $4.11(0.036)$ \\
Posterior Synechiae & $4.06(0.044)$ \\
Non-anterior location & $4.12(0.042)$ \\
Two or more factors & $0.69(0.41)$ \\
AC activity (cells) & $2.08(0.56)$ \\
AC Activity (flare) & $0.42(0.84)$ \\
\hline
\end{tabular}

Table 6. Univariate analysis of factors associated with visual impairment at 12 months of follow-up among patients with uveitis attended at KCMC Eye Department from 2010-2017 ( $=291)$.

\begin{tabular}{cccc}
\hline $\begin{array}{c}\text { Main predictors of visual } \\
\text { Impairment }\end{array}$ & $\mathrm{N}(\%)$ & OR $(95 \% \mathrm{CI})$ & $\chi^{2}$ (p value) \\
\hline Anatomical location & & $2.38(1.29-4.37)$ & $8.00(0.005)$ \\
Anterior & $58.0(24.6)$ & & \\
Non-anterior & $24.0(43.6)$ & & $5.76(0.056)$ \\
Clinical course & & $1.67(0.97-2.85)$ & \\
Acute & $50.0(24.9)$ & & $0.08(0.78)$ \\
Non-acute & $32.0(35.6)$ & & $8.61(0.003)$ \\
Cataract & $5.0(31.5)$ & $1.17(0.39-3.47)$ & $0.72(0.40)$ \\
Glaucoma & $25.0(43.9)$ & $2.43(1.33-4.43)$ & $0.16(1.00)$ \\
CME & $4.0(40.0)$ & $1.76(0.48-6.31)$ & $0.71(0.53)$ \\
Keratopathy & $2.0(22.2)$ & $0.72(0.15-3.55)$ & $8.91(0.007)$ \\
PS & $5.0(38.5)$ & $1.63(0.52-5.14)$ & $0.95(0.32)$ \\
RD & $6.0(75.0)$ & $8.17(1.61-41.36)$ & $7.11(0.008)$ \\
Phthisis & $2.0(50.0)$ & $2.59(0.36-18.68)$ & $2.55(0.14)$ \\
Maculopathy & $10.0(55.6)$ & $3.49(1.33-9.19)$ & $3.60(0.058)$ \\
Papillitis & $3.0(60.0)$ & $3.93(0.65-23.97)$ & $3.53(0.08)$ \\
Abnormal IOP & $17.0(40.5)$ & $1.91(0.97-3.77)$ & \\
Visual Impairment first visit & $106.0(48.0)$ & $1.50(0.98-2.28)$ & \\
\hline & & & \\
\hline
\end{tabular}

Table 7. Multivariate analysis of factors associated with visual impairment at 12 months follow-up, among patients with uveitis attended at KCMC Eye Department from 2010-2017 $(\mathrm{N}=291)$.

\begin{tabular}{cc}
\hline Predictors of visual Impairment & $\chi^{2}(\mathrm{p}$ value $)$ \\
\hline Non-anterior location & $2.11(0.15)$ \\
Glaucoma & $5.63(0.018)$ \\
RD & $5.22(0.022)$ \\
Maculopathy & $4.27(0.039)$ \\
\hline
\end{tabular}




\section{Discussion}

With regard to the proportion of visual impairment at presentation and at 12 months visit, we found a decrease of $29.5 \%$ (from $57.7 \%$ to $28.2 \%$ at presentation and at one year of follow-up respectively). This reduction of the proportion of visual impairment means that at twelve months of follow-up, approximately one third of patients still have visual impairment or blindness. Similar findings were reported in the studies by Amer et al., [11] and Durrani et al., [5] who reported proportions of visual impairment at presentation to be around $62 \%$ and $69 \%$ respectively. Different results were found by Groen and colleagues [6] in Netherlands who found proportion of visual impairment to be 35\%; and Zhang in China [12] reported higher proportion of visual impairment at first visit (72.7\%). The differences in proportions found by Groen and Zhang may be due to the fact that Groen only included patients referred from other hospitals (who might have had already been treated at referring centers, lowering the proportion of visual impairment at presentation) in his study; while Zhang only looked at patients with uveitis secondary to syphilis (all the patients had posterior involvement), whom may be severely affected thus giving high proportions of visual impaired participants at presentation. At 12 months, similar findings were reported in a study by Groen, which reported the proportion to be $26 \%$ and in our study we found $28.2 \%$. These similarities of proportion of visual impairment at 12 months might represent the real trend of visual improvement with time.

With regard to the mean visual acuity between presentation and 12 months visit, we found an overall statistically significant improvement of mean BCVA of $(0.26$, $\mathrm{p}$ value $<0.001)$, with presenting BCVA being $0.96 \log$ MAR and improving to $0.70 \log$ MAR. It means that broadly, these patients improved 2.6 lines; though in terms of visual impairment they remained in the same subcategory (Moderate Visual Impairment). These findings are similar to those reported by Amer and colleagues [11] who reported a mean BCVA of 0.85 Log MAR at presentation and 0.57 Log MAR at last follow-up. If medians are to be compared, we found a presenting median BCVA of 0.5 Log MAR and 0.3 log MAR at 12 months, although Bajwa in USA [7] and Zhang in China [12] had earlier reported medians of BCVA of 0.18 Log MAR both at presentation and at last follow-up and 0.3 Log MAR at presentation. These differences might reflect the differences on health care seeking behavior, which could make patients elsewhere seek treatment at the earlier stages of their disease than in our setting.

With regard to the factors associated with poor presenting visual acuity, the association between the Cataract and visual impairment $\left(\chi^{2}=33.69\right.$; $\mathrm{p}$ value $<$ 0.001) in this study, might just corroborate the well-known fact that cataract is an important cause of reversible visual impairment or blindness world-wide, as the medium opacity precludes light from surroundings to reach the posterior segment. Durrani in England [5] and Kempen and colleagues in a multicenter study [8] reported similar findings as Cataract was statistically significant associated with presenting poor visual acuity ( $\mathrm{p}$ value $=0.01$ and $\mathrm{p}$ value $=0.001$, respectively) in their studies. Similarly, CME was statistical significantly associated 
with poor vision $\left(\chi^{2}=13.75 ; \mathrm{p}\right.$ value $\left.<0.001\right)$. Macular lesion is associated with poor vision due to the macula importance in clear vision. These findings of association between CME and poor vision are similar with findings by Durrani in England [5]; and Rochepeau [9]; who found statistical significant association between CME and poor vision at presentation $(26.7 \%$; and $\mathrm{p}$ value $=0.009$ respectively). Abnormal IOP was also a statistical significant association with presenting poor vision $\left(\chi^{2}=4.11, \mathrm{p}\right.$ value $\left.=0.036\right)$ and this might be due to the alterations of cornea clarity associated for instance with abnormal high IOP or due to blurred view associated with lower pressures. Similar findings were reported earlier by Thorne [10] and Bajwa [7]; who found Abnormal IOP to be statistically significant association with presenting poor visual acuity $(79 \%$; $\mathrm{p}$ value $=0.04$ ); and by Bajwa (1.89 and 2.62 higher odds at presentation and one year respectively). Posterior synechiae held statistical significance $\left(\chi^{2}=4.06 ; \mathrm{p}\right.$ value $=$ 0.044 ) and it might be due to the reduction of the iris mobility which doesn't allow the control of the amount of light (restricting) entering into the eye. Posterior synechiae was also reported to be statistically significantly associated with poor vision ( $\mathrm{p}$ value $=0.005$ ) by Thorne $[10]$.

At 12 month of follow-up, factors associated with poor vision were Glaucoma $\left(\chi^{2}=5.63, \mathrm{p}\right.$ value $\left.=0.012\right)$; Retinal Detachment $\left(\chi^{2}=5.22, \mathrm{p}\right.$ value $\left.=0.022\right)$ and Maculopathy $\left(\chi^{2}=4.27, \mathrm{p}\right.$ value $\left.=0.039\right)$. The damages to the retina and to the optic nerve head caused by this two entities ( $\mathrm{RD}$ and Glaucoma respectively), are more likely to be the causes of the observed poor vision. Retinal detachment (75\%; $\chi^{2}=8.91, \mathrm{p}$ value $\left.=0.007\right)$ and Glaucoma $\left(43.9 \% ; \chi^{2}=8.61, \mathrm{p}\right.$ value $\left.=0.003\right)$ that were found to be statistically significantly associated with poor visual acuity in this study at last follow-up, were previously found respectively by Kempen [8] and Groen [6] to be statistically significantly associated with poor vision in their studies ( $\mathrm{p}$ value $=0.007$ and $\mathrm{p}$ value $=0.03$, respectively).

\section{Limitations}

One of the limitations of the study it was a retrospective cohort and patient's examination was done by different personnel; some files had missing (making them to be excluded). This may have led the study not to give the complete picture of the disease. Another important limitation is the loss of follow-up, i.e. patients who were not followed for 12 months or more were not included in the analysis of the key objectives of the study and they may have had interesting findings which could have given another image or complete picture (may not represent the whole population of uveitis patients).

\section{Conclusion}

Based on the results presented and discussed we can conclude that the proportion of visual impairment was high at presentation but it decreased significantly with timely treatment and follow-up. The mean/median BCVA changed timidly as it improved about 2 lines at a year. The predictors of poor vision at presentation and one year were complications of the disease and the management of 
those has contributed to visual improvement as most of them lost their statistical significance at one year of follow-up.

\section{Acknowledgements}

We would like to acknowledge the Light for the World project for funding this study and to Ms. Rachel Kimaro for her contribution during the data collection process.

\section{Conflicts of Interest}

The authors declare no conflicts of interest regarding the publication of this paper.

\section{References}

[1] Yanoff, M. and Duker, J.S. (2008) Ophthalmology. 3rd Edition, Elsevier, St. Louis, MO.

[2] Khurana, A.K. (2007) Comprehensive Ophthalmology. 4th Edition, New Age International, New Delhi.

[3] Bowling, B. (2016) Kanski's Clinical Ophthalmology. 8th Edition, Elsevier Limited, Sydney.

[4] Foster, S.C., Hinkle, D.M. and Opremcak, E. M. (2012) Curbside Consultation in Uveitis. SLACK Incorporated, Thorofare, NJ.

[5] Durrani, O.M., Tehrani, N.N., Marr, J.E., Moradi, P., Stavrou, P. and Murray, P.I. (2004) Degree, Duration, and Causes of Visual Loss in Uveitis. British Journal of Ophthalmology, 88, 1159-1162. https://doi.org/10.1136/bjo.2003.037226 6

[6] Groen, F., Ramdas, W., De Hoog, J., Vingerling, J.R. and Rothova, A. (2016) Visual Outcomes and Ocular Morbidity of Patients with Uveitis Referred to a Tertiary Center during First Year of Follow-Up. Eye (Basingstoke), 30, 473-480. https://doi.org/10.1038/eye.2015.269

[7] Bajwa, A., Lee, C.S., Patrie, J., Xin, W. and Reddy, A.K. (2015) Clinical and Visual Outcomes of Patients with Uveitis in the Mid-Atlantic United States. Clinical Ophthalmology (Auckland, N.Z.), 9, 1655-1664. https://doi.org/10.2147/OPTH.S88647

[8] Kempen, J.H., Natta, M.L., Van Alteweel, M.M., Dunn, J.P., Jabs, D.A., Lightman, S.L., et al. (2015) Factors Predicting Visual Acuity Outcome in Intermediate, Posterior, and Panuveitis: The Multicenter Uveitis Steroid Treatment (MUST) Trial. American Journal of Ophthalmology, 160, 1133-1141.

https://doi.org/10.1016/j.ajo.2015.09.017

[9] Rochepeau, C., Jamilloux, Y., Kerever, S., Febvay, C., Perard, L., Broussolle, C., et al. (2017) Long-Term Visual and Systemic Prognoses of 83 Cases of Biopsy-Proven Sarcoid Uveitis. British Journal of Ophthalmology, 101, 856-861. https://doi.org/10.1136/bjophthalmol-2016-309767

[10] Thorne, J.E., Woreta, F., Kedhar, S.R., Dunn, J.P. and Jabs, D.A. (2007) Juvenile Idiopathic Arthritis-Associated Uveitis: Incidence of Ocular Complications and Visual Acuity Loss. American Journal of Ophthalmology, 143, 840-846. https://doi.org/10.1016/j.ajo.2007.01.033

[11] Amer, R., Alsughayyar, W. and Almeida, D. (2017) Pattern and Causes of Visual Loss in Behçet's Uveitis: Short-Term and Long-Term Outcomes. Graefe's Archive for Clinical and Experimental Ophthalmology, 255, 1423-1432. https://doi.org/10.1007/s00417-017-3667-0

[12] Zhang, X., Du, Q., Ma, F., Lu, Y., Wang, M. and Li, X. (2017) Characteristics of Syphilitic Uveitis in Northern China. BMC Ophthalmology, 17, Article number: 95. https://doi.org/10.1186/s12886-017-0491-6 